\title{
Sex Differences in Ventilation amongst Athletes Undergoing EVH Challenge Testing for Exercise-Induced Bronchoconstriction
}

\author{
Nilam Akhtar Khan*, Martin R Lindley and Sarabjit S Mastana \\ School of Sport, Exercise and Health Sciences, Loughborough University, UK
}

\begin{abstract}
We aimed to report sex differences in ventilation during EVH challenge in University athletes while exploring whether they achieve inspiratory target. Seventy-seven athletes $(n=42$ males, $n=35$ females) performed six-minute EVH challenge involving compressed gas $\left(5 \% \mathrm{CO}_{2}, 21 \% \mathrm{O}_{2}\right.$ and balance $\left.\mathrm{N}_{2}\right)$ inhalation at an inspiratory target of $85 \% \mathrm{MVV}_{\text {indirect }}$ Ventilation was recorded every 15 seconds during $\mathrm{EVH}$ challenge with pre-and post-challenge measurements of $\mathrm{FEV}{ }_{1}$ determining outcomes. Males reached significantly higher ventilation $(412.0 \pm 55.0 \mathrm{~L})$ compared with female athletes $(292.5 \pm 43.2 \mathrm{~L}),(\mathrm{F}=3890.0, \mathrm{p}<0.05)$, and a significant effect of time $\left(\mathrm{F}_{(23)}=3689.8, \mathrm{p}<0.05\right)$ as well as interaction $(\mathrm{F}=$ $106.3, p<0.05)$ was noted. There were significant differences in cumulative ventilation attained $(679.5 \pm 146.6 \mathrm{~L})$ during the 6-min EVH compared with inspiratory target $(807.0 \pm 169.6 \mathrm{~L})$, amongst both sexes $\left(\mathrm{t}_{(76)}=5.0, \mathrm{p}<0.05\right)$ as well as EIB positive and negative groups $(p<0.05)$. The results support sex differences in ventilation achievement and suggest $\mathrm{EVH}$ inspiratory target of $85 \% \mathrm{MVV}_{\text {indirect }}$ is generally not reached by athletes, thereby requiring re-evaluation and further exploration of sex differences in future EVH studies.
\end{abstract}

\section{Keywords}

Exercise-induced bronchoconstriction, Sex differences, Eucapnic voluntary hyperpnea, Inspiratory target, Maximal voluntary ventilation

\section{Introduction}

Eucapnic voluntary hyperpnea (EVH) challenge is an easily standardised airway challenge which exhibits high sensitivity for detecting Exercise-Induced Bronchoconstriction (EIB) in the elite athlete population [1,2]. The EVH challenge is designed to promote breathing at high ventilation, allowing it to act as a surrogate to exercise. It has been used to diagnose EIB in various athletic populations, ranging from cold-weather Olympic athletes to national level athletes competing in long-distance running and speed and power games $[3,4]$.

Few studies have focused explicitly on game players who typically train in an outdoor environment and exhibit high levels of ventilation during training and play $[5,6]$. Game players such as field hockey or footballers perform high level exercise and therefore require high levels of ventilation, albeit in a sporadic or non-constant manner [7]. Data from elite female field hockey players highlight total distances covered during game play exceed $5 \mathrm{~km}$, and heart rates reach $96 \%$ of maximal heart rate $\left(\mathrm{HR}_{\max }\right)[8]$.

Despite the relative paucity of data focused upon female athlete ventilatory achievements in response to an EVH challenge, there is some evidence that demonstrates females are less likely to reach ventilatory targets than males [9]. In com- parison to age-matched males, females exhibit higher work of breathing at given ventilation and a higher susceptibility to expiratory flow limitation $[10,11]$. Although these differences in lung function do not necessarily translate into sex differences in EIB prevalence [12], current studies may be insufficient to note any sex differences due to the scarcity in studies recruiting female athletes [13]. Moreover, the female menstrual cycle and contraceptive use have been exhibited to exert effects upon ventilatory measurements, thereby requiring further investigation $[14,15]$.

Despite the generally reported fact that athletes do achieve set inspiratory target, there is no consensus on which inspiratory target should be used for EVH challenge in athletic

*Corresponding author: Nilam Akhtar Khan, School of Sport, Exercise and Health Sciences, Loughborough University, Epinal Way LE11 3TU Loughborough, UK

Accepted: October 15, 2020

Published online: October 17, 2020

Citation: Khan NA, Lindley MR, Mastana SS (2020) Sex Differences in Ventilation amongst Athletes Undergoing EVH Challenge Testing for Exercise-Induced Bronchoconstriction. Arch Sports Med 4(2):215-221 


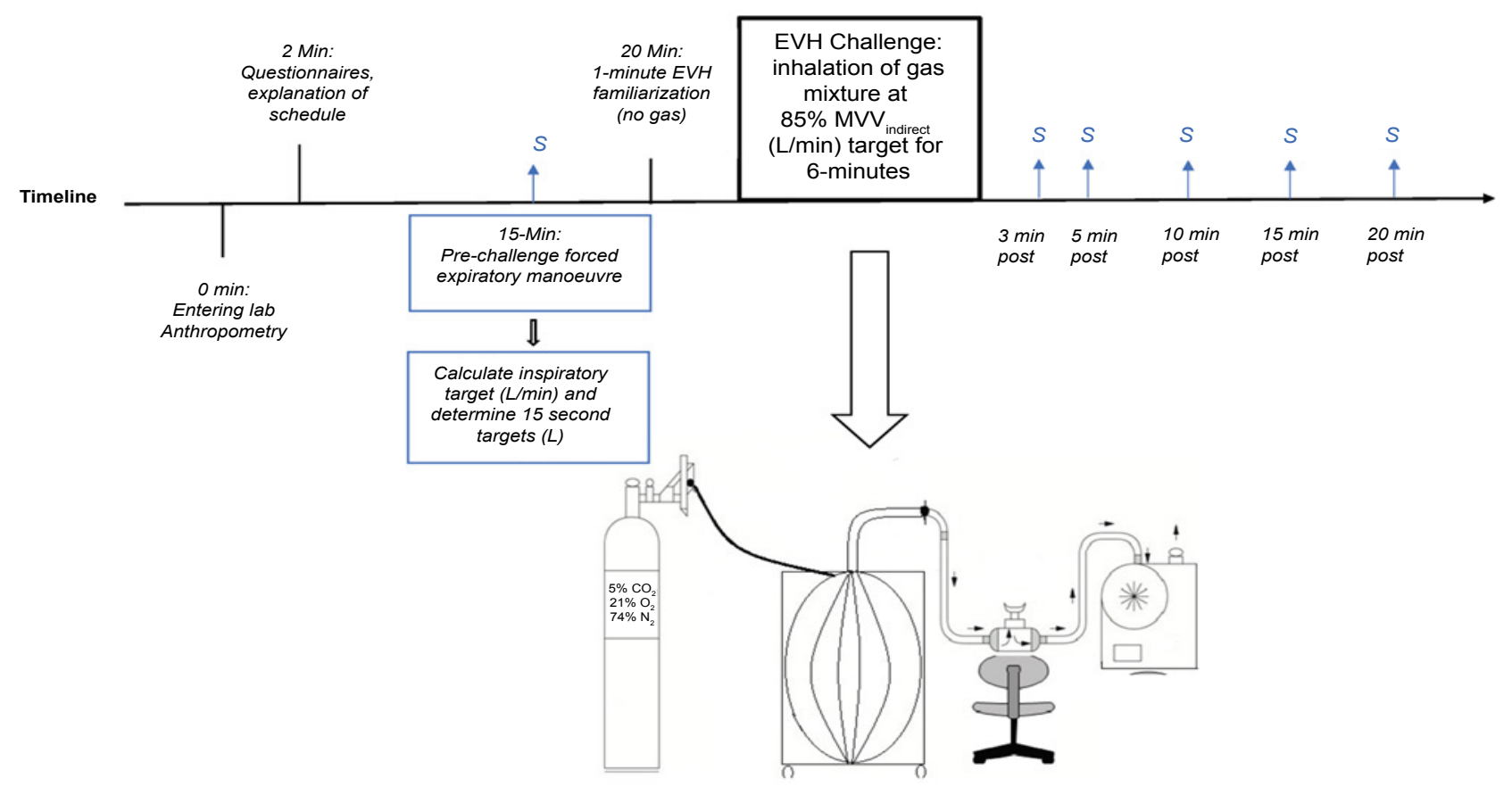

Figure 1: EVH laboratory set-up.

Laboratory set-up of Eucapnic voluntary hyperpnea challenge including pre- and post-EVH spirometry.

populations. However, $85 \%$ of the subject's maximum voluntary ventilation $\left(\mathrm{MVV}_{\text {indirect }}\right.$ ) or $30 \mathrm{x}$ forced expiratory volume in 1 second $\left(\mathrm{FEV}_{1}\right)$ have been typically employed [16]. More recent EIB investigations include reports of target ventilation, quantified through relative and absolute values $[17,18]$ and suggest some athletes may not necessarily achieve $100 \%$ of inspiratory target $[5,17]$. Earlier EIB studies argued that underperformance of the test allows for false-negative results and that the bronchoconstrictive response to EVH is directly proportional to inspiratory target, set at $30 \mathrm{xEV}_{1}$ [19]. Despite this, there is still limited reporting of ventilatory achievement during EVH challenge and a lack of data to allow investigation of male-female comparisons, especially in game players. In this study, we investigate ventilatory achievement in a sample of University athletes and assess male: female differences.

\section{Material and Methods}

Forty-two (42) male and thirty-five (35) female University athletes (hockey, football and rugby) participated in the study and were selected based on their regular training history and participation levels. Inclusion criteria were: Age between 18 to 25 years, non-smokers, free from illness or injury and history of elite-level competition. The study was approved by the Loughborough University Ethical Advisory Committee and conducted according to the Declaration of Helsinki (World Medical Association, 2004). All participants signed informed consent and completed health screen questionnaires. Female athletes were tested during the follicular phase of the menstrual cycle (days 1-8) identified by a questionnaire to reduce variation in ventilation [15].

EVH challenge was conducted following standardised guidelines with reference to medication, exercise, alcohol and caffeine $[16,20]$. Pre- and post-EVH spirometry measurements were performed as per American Thoracic Society and European Respiratory Society (ATS/ERS) criteria for spirometry testing [21], using Micro Loop spirometer (Micro Medical/Williams Medical supplies, Rhymney, Gwent, UK). Upon completion of $\mathrm{EVH}$, the percentage fall in $\mathrm{FEV}_{1}$ was calculated using the following formula:

$$
\frac{\text { Pre-challenge } \mathrm{FEV}_{1} \text { - Post-challenge } \mathrm{FEV}_{1}}{\text { Pre-challenge FEV }} \times 100
$$

A drop in $\mathrm{FEV}_{1} \geq 10 \%$ at two consecutive time-points was recorded as EIB positive outcome (Figure 1).

Prior to bronchoprovocation with $\mathrm{EVH}$, inspiratory target was set at 85 percent of maximal voluntary ventilation (MV$\mathrm{V}_{\text {indirect }}$ ), which was derived from maximal pre-challenge $\mathrm{FEV}_{1}$. EVH was performed as per previously published protocol [16] with participants inhaling a supply of compressed air with five percent carbon dioxide ( $21 \%$ oxygen and balance nitrogen) (BOC group, part number: 280890; Surrey, UK) via a mouthpiece attached to a T-shaped two-way non-rebreathing valve (Hans Rudolph Valve No. 2700, Kansas City, Mo). A digital display on a dry gas meter exhibited volume of air expired to the nearest decimal, allowing visual feedback regarding individual inspiratory target. Participants were coached rigorously with verbal encouragement. Achieved ventilation values were recorded every 15 seconds, allowing for an exact determination of $\dot{V}_{E}$ (L/min) for each minute of the challenge. Prior to the six-minute $\mathrm{EVH}$ challenge using gas $\operatorname{mix}\left(5 \% \mathrm{CO}_{2}\right)$, participants underwent a one-minute familiarisation period breathing room air in order to practise individual rate and depth of breathing required to reach inspiratory target. A rest period followed between the familiarisation and the EVH challenge. 
Citation: Khan NA, Lindley MR, Mastana SS (2020) Sex Differences in Ventilation amongst Athletes Undergoing EVH Challenge Testing for Exercise-Induced Bronchoconstriction. Arch Sports Med 4(2):215-221

Table 1: Anthropometry and spirometry measurements recorded prior to EVH challenge in male and female athletes.

\begin{tabular}{|l|l|l|l|l|l|l|l|}
\hline Sex & $\begin{array}{l}\text { No of } \\
\text { subjects }\end{array}$ & $\begin{array}{l}\text { Age range } \\
\text { (yr) }\end{array}$ & Height $(\mathbf{c m})$ & Weight $(\mathbf{k g})$ & $\begin{array}{l}\text { FEV }_{\mathbf{1}} \text { baseline } \\
\text { (Litres) }\end{array}$ & $\begin{array}{l}\text { FEV }_{\mathbf{1}} / \text { FVC baseline } \\
\text { (\%) }\end{array}$ & $\begin{array}{l}\text { FVC baseline } \\
\text { (Litres) }\end{array}$ \\
\hline Female & 35 & $18-25$ & $165.3 \pm 6.0^{*}$ & $66.1 \pm 6.7^{*}$ & $3.5 \pm 0.5^{*}$ & $85.9 \pm 6.1$ & $4.1 \pm 0.5^{*}$ \\
\hline Male & 42 & $18-24$ & $179.2 \pm 6.4^{*}$ & $77.1 \pm 7.0^{*}$ & $4.8 \pm 0.7^{*}$ & $85.7 \pm 4.6$ & $5.6 \pm 0.9^{*}$ \\
\hline
\end{tabular}

*denotes significant differences between males and females, accepted at $p<0.05$

Data for age, height, weight and spirometry are expressed in means \pm standard deviation.

\section{Statistical analysis}

Statistical analyses were performed using IBM SPSS v.24 software. Means and standard deviations were used to report data. Normality of the data was confirmed using Shapiro-Wilks tests. Independent two-tail t-tests were used to calculate differences in anthropometry and ventilation across sexes and EIB groups. Mixed model repeated measures ANOVAs were used to compare ventilation every 15 seconds between groups. Two tail t-tests were used to explore differences between cumulative and target ventilation. Significance was set at $p$-value $\leq 0.05$, with Bonferroni correction applied to multiple comparisons.

\section{Results}

Participant characteristics are summarised in (Table 1). There are significant differences in anthropometric (weight $\mathrm{t}_{(75)}=-7.2, \mathrm{p}<0.05$; and height $\left.\mathrm{t}_{(75)}=-9.8, \mathrm{p}<0.05\right)$ and baseline lung function indices $\left(\mathrm{FEV}_{1} \mathrm{t}_{(75)}=-9.7, \mathrm{p}<0.05\right.$; and FVC $\left.t_{(75)}=-9.8, p<0.05\right)$ between male $(n=42)$ and female $(n=$ $35)$ athletes. The lowest $\mathrm{FEV}_{\text {1predicted }}$ recorded was $73 \%(2.56 \mathrm{~L})$ amongst females and $86 \%(3.67 \mathrm{~L})$ amongst males. The highest FEV 1predicted was $125 \%(4.47 \mathrm{~L})$ and $128 \%(6.29 \mathrm{~L})$ respectively. All participants demonstrated $\mathrm{FEV}_{1}$ predicted values and $\mathrm{FEV}_{1} / \mathrm{FVC}$ ratios above $70 \%$ [22].

Twelve athletes ( 7 males: 5 females) were EIB positive and the remaining 65 athletes were EIB negative. There were no differences noted in anthropometry or baseline $\mathrm{FEV}_{1}$ and FVC between EIB positive $(n=12)$ and negative $(n=65)$ athletes.

A mixed measures ANOVA shows a significant main effect of time $\left(\mathrm{F}_{(23)}=3689.8, \mathrm{p}<0.05\right.$ all 24 time-points, with Bonferroni correction) and significantly higher mean ventilation achieved by male (mean $412.0 \pm 55.0 \mathrm{~L}$ across all time-points) compared with female (292.5 \pm 43.2 Litres, mean across all time-points) athletes $(F=3890.0, p<0.05)$, as well as a significant interaction $(F=106.3, p<0.05)$ between sex and time (Figure 2).

An inspiratory target was set at $85 \% \mathrm{MVV}_{\text {indirect }}$. Males reach an average of $85.6 \pm 10.0 \%$ and females attain $83.4 \pm$ $9.4 \%$ of target. Unpaired t-test analysis shows no difference in relative achievement between sexes $\left(t_{(75)}=-1.0, p=0.32\right)$.

As an overall group, athletes did not attain (679.5 \pm 146.6 $\mathrm{L}$ achievement) inspiratory target set at $85 \% \mathrm{MVV}_{\text {indirect }}$ (corresponding to $807.0 \pm 169.6 \mathrm{~L})$, $\left(t_{(76)}=5.0, p<0.05\right)$. When the group is divided into males $(782.5 \pm 102.0 \mathrm{~L}$ vs. $921.5 \pm 132.6$ $\left.L, t_{(41)}=-8.6, p<0.05\right)$ and females $(556.0 \pm 82.0$ L vs. $669.5 \pm$
85.9 $L, t_{(34)}=-9.8, p<0.05$ ), the same is noted (Figure 3 ).

There was no difference in relative achievement of ventilation by EIB negative; $84.7 \pm 9 \%$ compared with EIB positive athletes; $84.3 \pm 12 \%\left(t_{(75)}=-0.1, p=0.91\right)$. Total ventilation reached throughout 6-min EVH was also similar, with EIB positive athletes $(n=12)$ reaching $630.1 \pm 146.8 \mathrm{~L}$ and negative athletes $(n=65)$ reaching $688.6 \pm 145.9 L, t_{(15)}=-1.3, p=0.22$.

Eighteen female athletes were currently taking contraceptive pills. A mixed measures ANOVA shows a significant main effect of time $\left(F_{(23)}=1553.2, p<0.05\right.$ all 24 time-points, Bonferroni correction) but no significant difference in achieved ventilation ( $F=2.1, p=0.16$ ) between females reporting oral contraceptive use $(n=18,302.4 \pm 47.1 \mathrm{~L}$ ) compared with those not taking contraceptives ( $n=17,282.0 \pm 37.1 \mathrm{~L}$ ) (Figure 4). There was a significant interaction $(F=2.6, p<0.05$ Greenhouse-Geisser correction) between $\mathrm{OC}$ use and time.

\section{Discussion}

The primary aim of this study was to make comparisons in male and female ventilatory achievement during EVH challenge testing for EIB in a group of elite University based game players. Our main finding exhibits a sex difference in ventilation consistently throughout six-minute EVH challenge. The results are comparable to findings by Brummel, et al. who demonstrated that EVH inspiratory target (at 60\% $\mathrm{MVV}_{\text {indirect }}$ ) was 2.38 times less likely reached by female, in contrast to male patients (including athletes) referred for EIB assessment [9]. The authors further noted females exhibited significantly higher EIB outcome than males although EIB prevalence did not differ between sexes in our study. There is evidence which supports the view that female athletes should perform better during hyperpnea than female non-athletes, thereby making it difficult to apply findings by Brummel, et al., which included patients, to athletic populations. The consequence of differences in fitness level is thought to cause greater usage of ventilatory reserves and greater expiratory flow limitation amongst fit compared with less fit women [23].

Similarly, Stadelmann, et al. demonstrated significant differences in achieved ventilation between female ( $n=9$, reaching $81 \%$ of inspiratory target) and male $(n=15 ; 87 \%$ of inspiratory target at $85 \% \mathrm{MVV}_{\text {direct }}$ ) swimmers [24]. We did not observe a sex difference in relative ventilation but instead observed both sexes were similarly 'off-target'. Our study provides novel insight as both absolute and relative ventilations were reported for the first time.

There is concern regarding female contraceptive use 
A.

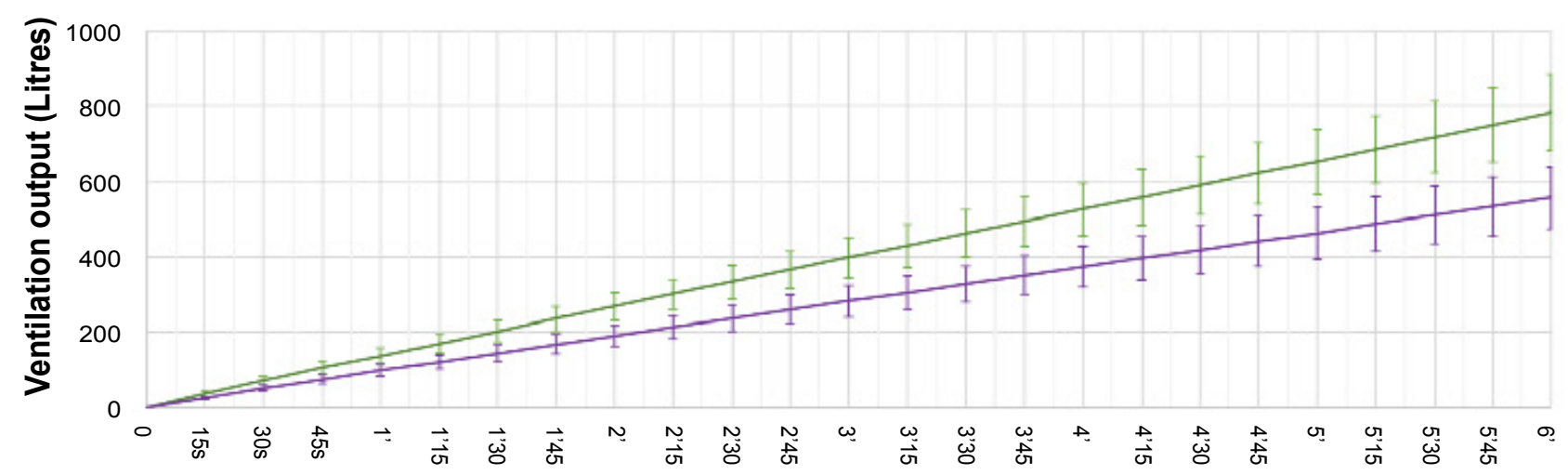

EVH time-point (min, sec)

B.

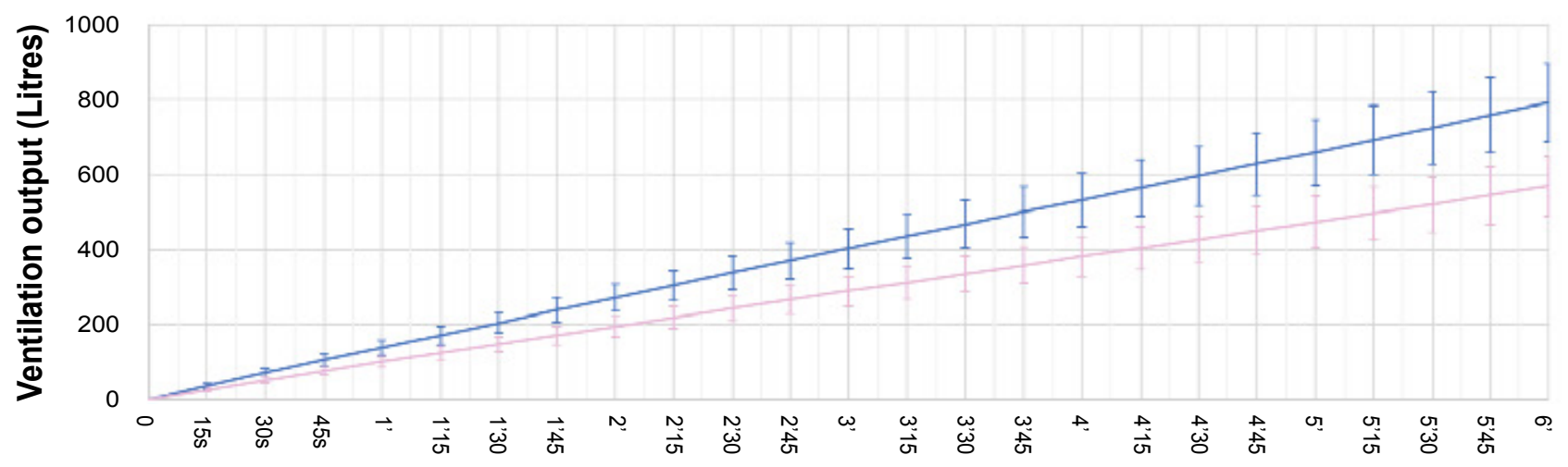

EVH time-point (min, sec)

C.

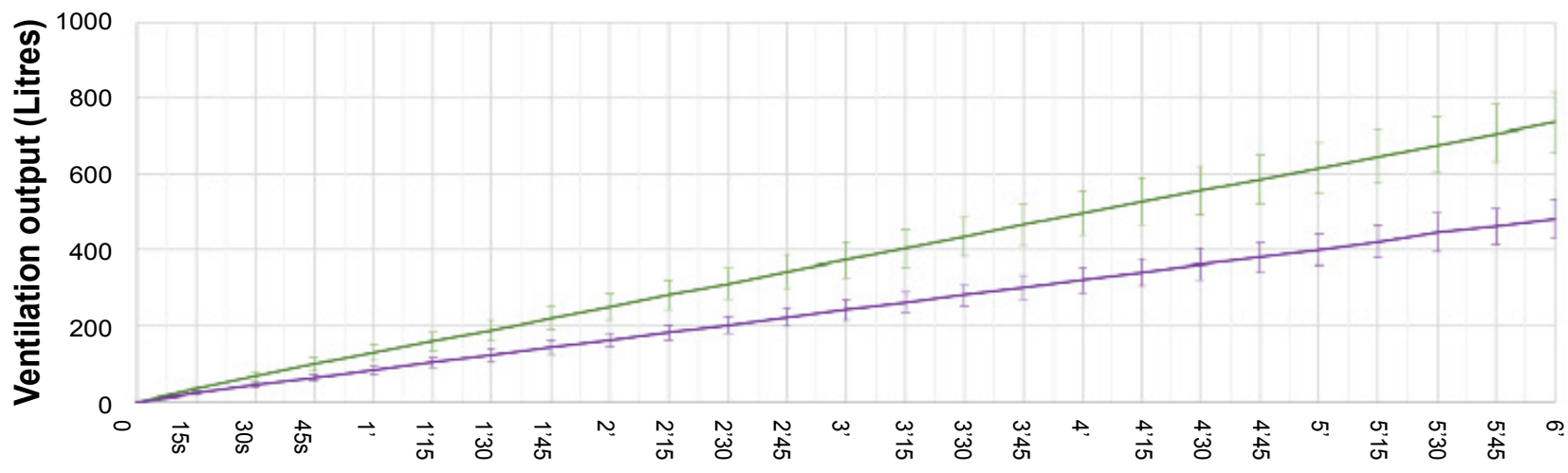

EVH time-point (min, sec)

Figure 2: Attained ventilation every 15 sec during $\mathrm{EVH}$ ( $\mathrm{M}$ and $\mathrm{F})$.

The plots highlight achievement of ventilation every 15 seconds during 6-min EVH challenge in male (top lines and bars) and female (bottom lines and bars) athletes. Panel A corresponds to sex differences in whole population ( $n=42$ males vs. $n=35$ females), panel $B$ only shows EIB negative athletes ( $n=35$ males vs. $n=30$ females) whereas panel C represents EIB positive athletes ( $n=7$ males vs. $n$ $=5$ females).

NB: Values displayed in panel $\mathrm{C}$ should be interpreted with caution due to a small sample size. 
A.

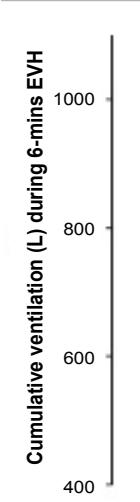

C.

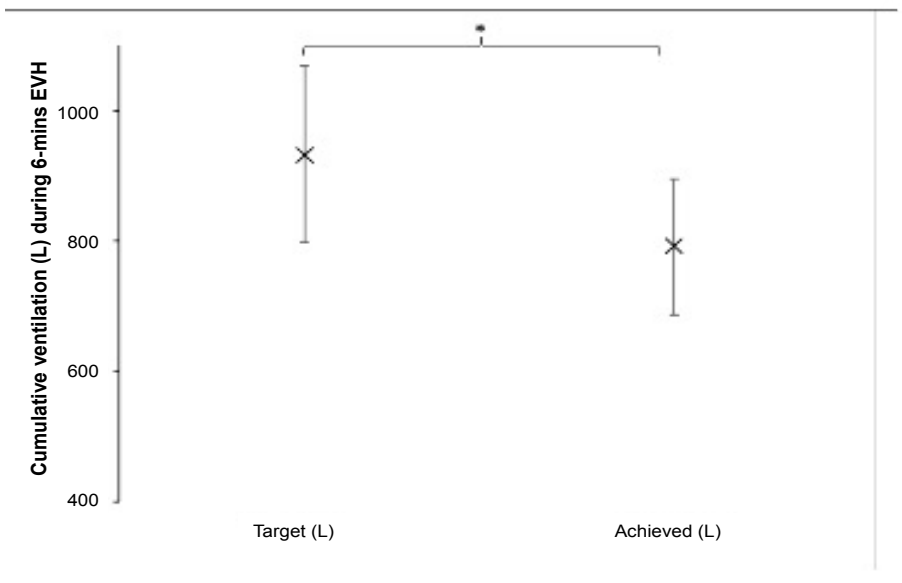

E.

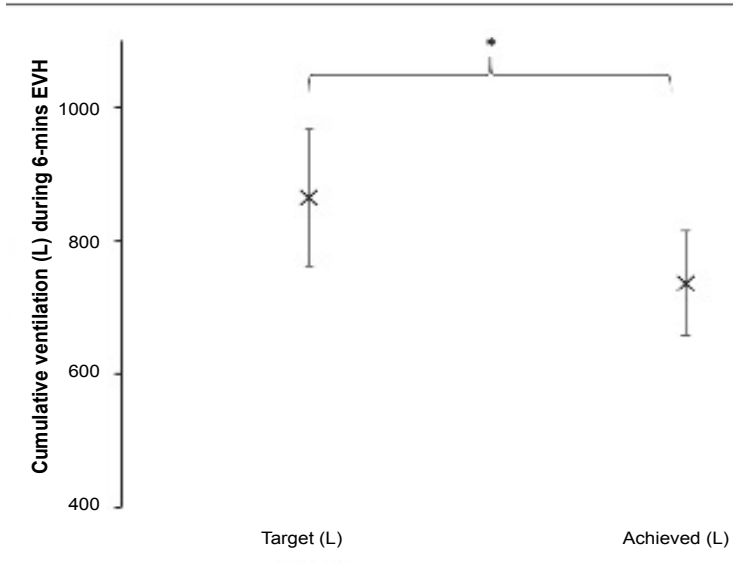

B.

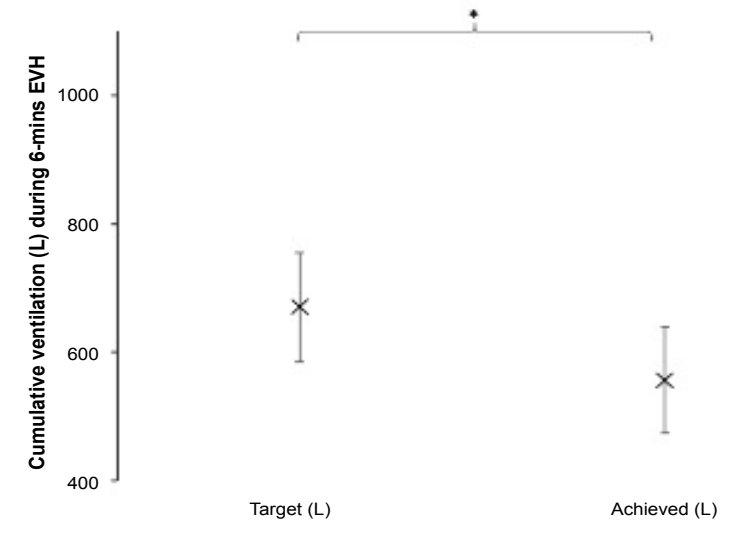

D.
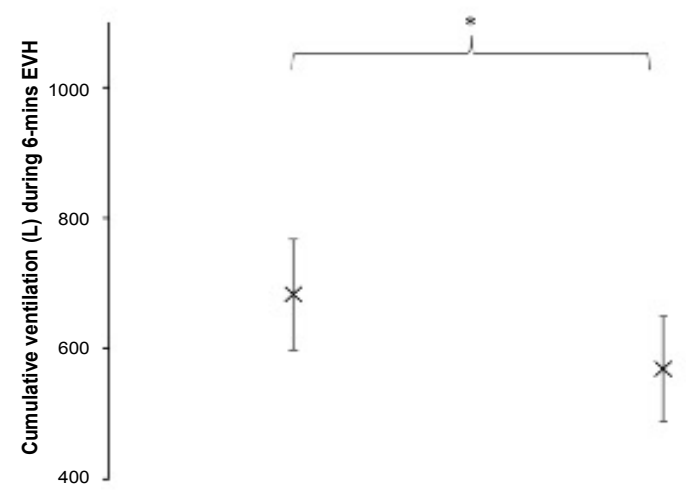

Target (L)

Achieved (L)

F.
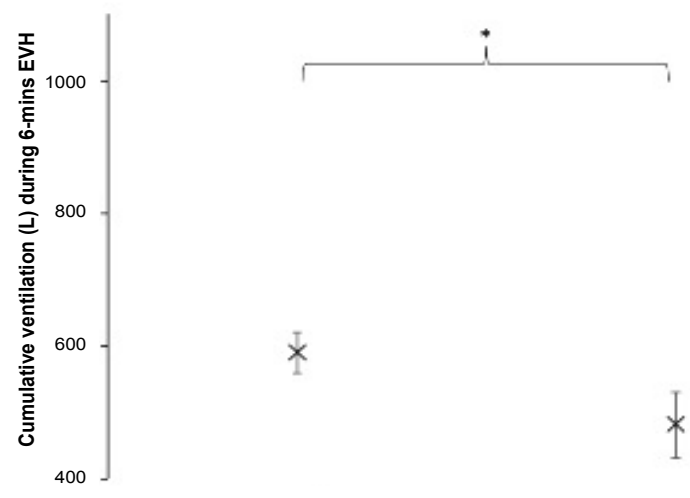

Target (L)

Achieved (L)

Figure 3: Differences in target and achieved ventilation.

Significant differences between cumulative target and achieved ventilation during 6-min EVH challenge amongst all male ( $n=42$, panel A) and female $(n=35$, panel B) athletes. Significant differences between target and achievement is also noted amongst EIB negative males ( $n=35$, panel C), EIB negative females $(n=30$, panel D), EIB positive males ( $n=7$, panel E) and EIB positive females $(n=5$, panel F). Significance is denoted as *, accepted at $p<0.05$.

during athletic training and competition [14]. The current study demonstrated no difference in ventilation during 6-min $\mathrm{EVH}$ between females self-reporting contraceptive use in comparison to those who did not take contraceptives. Although this novel finding requires further research to support or negate the lack of impact of female contraceptive use, it 


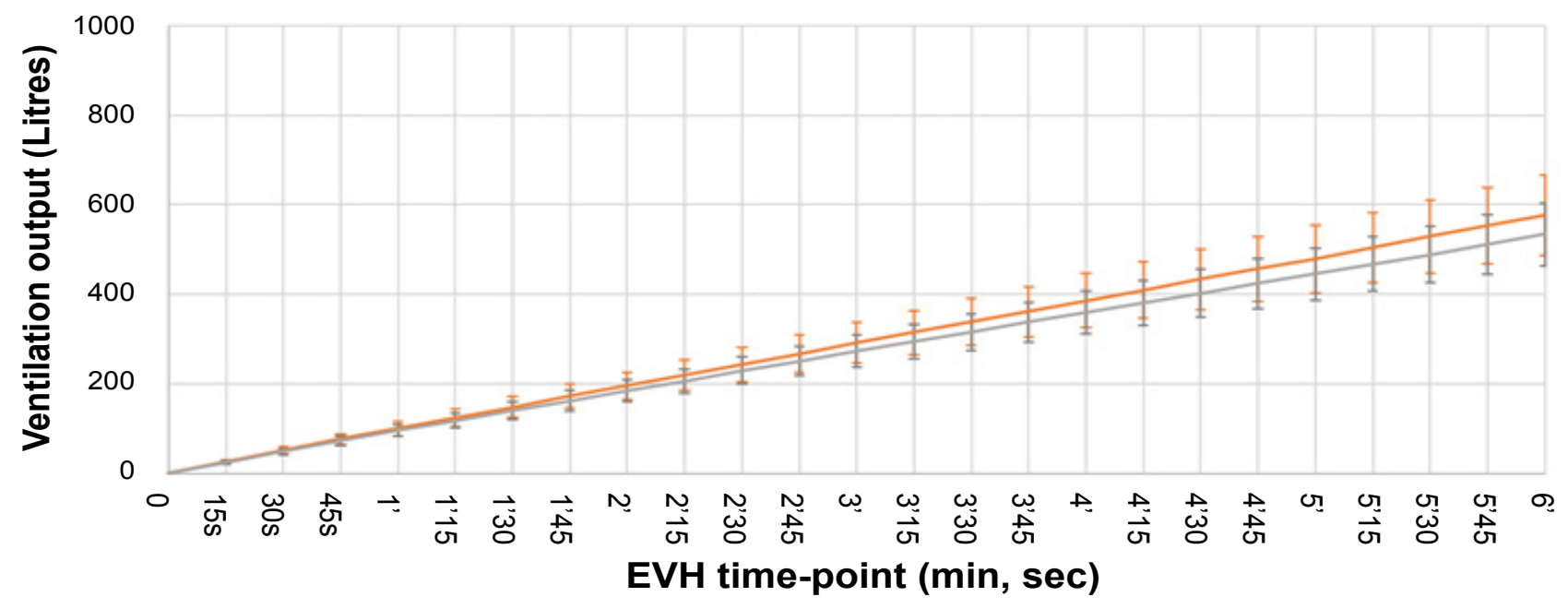

Figure 4: Attained ventilation (15 sec) in females with \& without contraceptives.

Females on contraceptive pills ( $n=18$, orange) and those using no contraceptive pills ( $n=17$, grey) achieve similar ventilation every 15 sec during six-minute EVH challenge.

may enhance much-needed debate around contraceptive use during female athletes' competition and game play [25]. Future studies may benefit from comparisons between different types and doses of oral contraceptives, which have been shown to exhibit varying effects on exercise [26].

A secondary aim of this study was to assess if athletes undergoing six minutes of EVH challenge reach $85 \% \mathrm{MVV}_{\text {in }}$ direct inspiratory target. In addition to a failure of athletes to reach inspiratory targets, no differences in relative ventilations were noted between EIB positive and negative groups, which is comparable to previous literature suggesting EIB diagnosis does not impact outcome from EVH challenge [9]. Our findings, therefore, question continued use of target at $85 \%$ $\mathrm{MVV}_{\text {indirect }}$ for $\mathrm{EVH}$ challenge in athletes. Further studies are required to refute its use while simultaneously investigating if alternative targets such as $30 \times \mathrm{FEV}_{1}$ or $21 \times \mathrm{FEV}_{1}$ may be more suitable.

EIB studies investigating sex differences in ventilation achievement are currently sparse although some support exists for underperformance during EVH challenge, prominently amongst female athletes $[9,24]$. Underlying mechanisms owing to the lack in athletes achieving inspiratory target are not fully elucidated, although causes may be multifactorial e.g. lack of effort and respiratory muscle fatigue. Since effort may prove difficult to assess quantitatively, respiratory muscle fatigue in athletes with larger lungs and presence of underlying airway inflammation in EIB positive athletes may act as plausible theories. Indeed, some of the athletes with large lungs in the current study produced above-average $\mathrm{MVV}_{\text {indirect }}$ targets, exceeding $170 \mathrm{~L} / \mathrm{min}$ (ten male footballers and hockey players). A high level of sustained ventilatory output exceeding $125 \mathrm{~L} / \mathrm{min}$ has been shown to contribute to diaphragmatic fatigue [27]. However, in order to quantify the presence of respiratory muscle fatigue, additional tests such as muscle inspiratory pressure measurements or body plethysmography would be required, which represents a novel opportuni- ty for future EVH studies. In such context, quantification of achieved ventilation during $\mathrm{EVH}$, such as that carried out in the current study, may add value to findings.

\section{Perspective}

The current study for the first time quantifies and notes significant ventilatory sex differences during EVH challenge, thereby presenting a novel method allowing for cross-comparison between and within EIB studies. Our study adds support to previous research which noted EVH inspiratory target at $85 \% \mathrm{MVV}_{\text {indirect }}$ is too high for athletes, consequently questioning its continued use. Since overall literature supporting or refuting ventilatory sex differences is sparse, it is suggested that future EIB studies quantify these, alongside further exploring effect of contraceptives on ventilatory parameters amongst female athletes.

\section{Acknowledgments}

The authors are extremely grateful to relevant team coaches and individual athletes from Loughborough University British Universities and Colleges Sport (BUCS) leagues who supported this study.

\section{Disclosure Statement}

No conflict of interest was reported by the authors.

\section{References}

1. Wilber RL, Rundell KW, Szmedra L, et al. (2000) Incidence of exercise-induced bronchospasm in olympic winter sport athletes. Med Sci Sports Exerc 32: 732-737.

2. Fitch KD, Sue-Chu M, Anderson SD, et al. (2008) Asthma and the elite athlete: Summary of the international Olympic committee's consensus conference, Lausanne, Switzerland, January 22-24, 2008. J Allergy Clin Immunol 122: 254-260.

3. Helenius IJ, Tikkanen HO, Haahtela T (1997) Association between type of training and risk of asthma in elite athletes. Thorax 52: 157-160. 
Citation: Khan NA, Lindley MR, Mastana SS (2020) Sex Differences in Ventilation amongst Athletes Undergoing EVH Challenge Testing for Exercise-Induced Bronchoconstriction. Arch Sports Med 4(2):215-221

4. Khan DA (2012) Exercise-induced bronchoconstriction: Burden and prevalence. Allergy Asthma Proc 33: 1-6.

5. Ansley L, Kippelen P, Dickinson J, et al. (2012) Misdiagnosis of exercise-induced bronchoconstriction in professional soccer players. Allergy 67: 390-395.

6. Selge C, Thomas S, Nowak D, et al. (2016) Asthma prevalence in German Olympic athletes: A comparison of winter and summer sport disciplines. Respir Med 118: 15-21.

7. Drust $B$, Atkinson G, Reilly $T$ (2007) Future perspectives in the evaluation of the physiological demands of soccer. Sports Med 37: 783-805.

8. McGuinness A, Malone S, Petrakos G, et al. (2017) The physical and physiological demands of elite international female field hockey players during competitive match-play. J Strength Cond Res 33: 3105-3113.

9. Brummel NE, Mastronarde JG, Rittinger D, et al. (2009) The clinical utility of eucapnic voluntary hyperventilation testing for the diagnosis of exercise-induced bronchospasm. J Asthma 46: 683686.

10. Dominelli PB, Render JN, Molgat-Seon Y, et al. (2015) Oxygen cost of exercise hyperpnea is greater in women compared with men. J Physiol 593: 1965-1979.

11. Sheel WA, Dominelli PB, Molgat-Seon Y (2016) Revisiting dysanapsis: Sex-based differences in airways and the mechanics of breathing during exercise. Exp Physiol 101: 213-218.

12. Becerril-Angeles M, Vargas MH, Hernandez-Perez L, et al. (2017) Prevalence and characteristics of exercise-induced bronchoconstriction in high school and college athletes at 2,240 $\mathrm{m}$ altitude. Rev Invest Clin 69: 20-27.

13. Costello JT, Bieuzen F, Bleakley CM (2014) Where are all the female participants in sports and exercise medicine research? Eur J Sport Sci 14: 847-851.

14. Duke JW (2017) Sex Hormones, Exercise and Women. In: Hackney A, ed. Sex Hormones, Exercise and Women. 19-34.

15. Stanford KI, Mickleborough TD, Ray S, et al. (2006) Influence of menstrual cycle phase on pulmonary function in asthmatic athletes. Eur J Appl Physiol 96: 703-710.
16. Anderson SD, Argyros GJ, Magnussen H, et al. (2001) Provocation by eucapnic voluntary hyperpnea to identify exercise induced bronchoconstriction. Br J Sports Med 35: 344-347.

17. Van der Eycken S, Schelpe A, Marijsse G, et al. (2016) Feasibility to apply eucapnic voluntary hyperventilation in young elite athletes. Respir Med 111: 91-93.

18. Kennedy MD, Steinback CD, Skow R, et al. (2017) Is performance of a modified eucapnic voluntary hyperpnea test in high ventilation athletes reproducible? Allergy Asthma Immunol Res 9: 229-236.

19. Spiering BA, Judelson DA, Rundell KW (2004) An evaluation of standardizing target ventilation for eucapnic voluntary hyperventilation using FEV1. J Asthma 41: 745-749.

20. Crapo RO, Casaburi R, Coates AL, et al. (2000) Guidelines for methacholine and exercise challenge testing-1999. This official statement of the American thoracic society was adopted by the ATS board of directors, July 1999. Am J Respir Crit Care Med 161: 309-329.

21. Miller MR, Hankinson J, Brusasco V, et al. (2005) Standardisation of spirometry. Eur Respir J 26: 319-338.

22. Pellegrino R, Viegi G, Brusasco V, et al. (2005) Interpretative strategies for lung function tests. Eur Respir J 26: 948-968.

23. McClaran SR, Harms CA, Pegelow DF, et al. (1998) Smaller lungs in women affect exercise hyperpnea. J Appl Physiol 84: 1872-1881.

24. Stadelmann K, Stensrud T, Carlsen KH (2011) Respiratory symptoms and bronchial responsiveness in competitive swimmers. Med Sci Sports Exerc 43: 375-381.

25. Khan NA, Lindley MR (2017) Sex differences in athletes with asthma and exercise-induced bronchoconstriction: Future directions.

26. Burrows M, Peters CE (2007) The influence of oral contraceptives on athletic performance in female athletes. Sport Med 37: 557-574.

27. Johnson BD, Babcock MA, Suman OE, et al. (1993) Exercise-induced diaphragmatic fatigue in healthy humans. J Physiol 460: 385-405. 